\title{
Envolvendo a Comunidade na Melhoria da Qualidade e Humanização dos Cuidados de Saúde: um Princípio de uma Abordagem
}

\author{
Cala, Ana de Lurdes; Nhatave, Isabel Ana; Cunha, Morais M. Cardoso da \\ Ministério da Saude _-a_cala@yahoo.com.br
}

\begin{abstract}
Introdução: Segundo os Planos Estratégicos do Sector Saúde (PESS), 2007-2012 e 2013-2017, deve-se assegurar a melhoria da qualidade do atendimento aos utentes no Serviço Nacional de Saúde (SNS). a Estratégia Nacional para a Melhoria da Qualidade e Humanização dos Cuidados de Saúde, 2011-2013, identifica a melhoria da qualidade e humanização (MQ\&H) como resultado dos esforços conjuntos envolvendo provedores, utentes e comunidade organizados em comités. no país, o envolvimento e participação comunitária tem longas tradições, e essa experiência foi partilhada na Conferência Internacional sobre Cuidados de Saúde Primários, de Alma-Ata 1978, que na sua Declaração Final estabelece que o envolvimento comunitário em Saúde é de primordial importância e factor chave para o desenvolvimento humano e que as populações têm o dever de participar em acções que visam melhorar e preservar a sua Saúde. Objectivo: Descrever o processo e estruturas de envolvimento da comunidade na MQ\&H dos cuidados de saúde conduzido pelo MISAU e factores determinantes da sua participação. Metodologia: o trabalho foi produzido a partir da revisão bibliográfica no período de Março de 2011 a Dezembro de 2013 utilizando processos de análise e síntese da informação de documentos estratégicos e artigos publicados e não publicados sobre Q\&H, e apoiado em referências internacional. Foram também tomados em consideração registos de relatos de pessoas que directa ou indirectamente participaram no processo. Resultados: Durante os primeiros 2 anos de implementação das Estratégia Nacional de MQ\&H, o MISAU facilitou a criação de 201 comités de Q\&H com mais de 2500 membros. Cerca de $60 \%$ dos membros dos comités provincial, distrital e de unidade sanitária (US) é composta por membros da comunidade e sociedade civil. nos sectores das US existem equipas de Q\&H que incluem representantes das comunidades e que são responsáveis pelos processos transformativos rumo a MQ\&H. São canais de articulação, reuniões de planificação e seguimento das actividades; reuniões regionais e nacionais de balanço e partilha de experiências; a participação na gestão da opinião pública e avaliações de desempenho; e em reuniões do governo na comunicação das necessidades, progressos e advocacia para aumento de recursos. Conclusão: Os Comités de Q\&H têm permitido o estabelecimento de parcerias entre o SNS-comunidade-ONGs proporcionando-Ihes oportunidades de participação ampla e maior compromisso com o processo. Apesar destes progressos, o sector precisa de melhorar a definição e promoção do cumprimento do papel dos intervenientes, particularmente dos líderes comunitários; a consciencialização dos trabalhadores de saúde sobre a importância do contributo da comunidade; a garantia de fundos; a provisão de incentivos aos líderes comunitários; e a expansão dos comités maximizando as oportunidades de integração.
\end{abstract}

Cala, Ana de Lurdes; Nhatave, Isabel Ana; Cunha, Morais M. Cardoso da. Envolvendo a Comunidade na Melhoria da Qualidade e Humanização dos Cuidados de Saúde: um Princípio de uma Abordagem. In: Anais do Congresso Internacional de Humanidades \& Humanização em Saúde [= Blucher Medical Proceedings, num.2, vol.1]. São Paulo: Editora Blucher, 2014. ISSN 2357-7282

DOI 10.5151/medpro-cihhs-10634 